\title{
The Auditory Brainstem Response - Are South African ENT's Missing the Point?
}

\author{
Antonia Sahli, Shamim Ebrahim and Wayne J Wilson
}

Department of Speech Pathology and Audiology,

University of the Witwatersrand, South Africa

\begin{abstract}
The use and misuse of the auditory brainstem response $(A B R)$ test by hearing professionals is often related to the extent and nature of the training they have received. This study used a postal survey based questionnaire to investigate the levels of training in, knowledge about, and appropriateness of referral for, $A B R$ testing in Ear, Nose and Throat (ENT) surgeons and registrars in Gauteng, South Africa. Thirty-seven actively practising ENT specialists and registrars were sampled using a convenience sampling technique. Overall, a poor level of training and knowledge in ABR and its related areas of audiology was identified. This was mirrored by a high demand for further education. Considering the prevalence of auditory disorders in South Africa, and the push towards primary care and early intervention, this study's results highlight the need for improved training in $A B R$ for ENT surgeons and registrars.
\end{abstract}

\section{OPSOMMING}

Die gebruik en misbruik van die ouditiewe breinstamrespons (OBR) toets deur professionele individue gemoeid met gehoor, hang dikwels af van die aard en omvang van die opleiding wat hulle ontvang het. Hierdie studie het deur middel van 'n posvraelys, die vlakke van opleiding, kennis, en toepaslikheid van verwysings vir OBR-toetsing deur' $n$ groep Oor-, Neus-en Keelartse (ONK) in Gauteng, Suid-Afrika, ondersoek. Sewe en dertig praktiserende ONK -artse en kliniese assistente is deur middel van 'n gerieflikheidssteekproeftegniek geselekteer. 'n Algemene gebrek aan opleiding en 'n lae vlak van kennis oor OBR en verwante terreine van oudiologie is geïdentifiseer. Terselfdertyd is daar 'n uitgesproke behoefte aan verdere opleiding. In die lig van die hoë voorkoms van gehoorprobleme in Suid-Afrika en die voorkoming en vroeë intervensie, dui die resultate van hierdie studie op ' $n$ besliste behoefte aan verbeterde opleiding oor OBR onder Oor-, Neus-, en Keelartse.

KEYWORDS: auditory brainstem response, Ear Nose and Throat Surgeons and Registrars, training, knowledge.

\section{INTŔ́ODUCTION}

The auditory brainstem response (ABR) has been the mainstay of the advanced audiological and ENT neuro-otological test battery since its clinical introduction in the late 1970's (Hall, 1992; Ferraro \& Durrant, 1994). It is a farfield, differentially averaged, electrophysiologically recorded signal that represents the summed and averaged responses to repeated acoustic stimulation, of thousands of nerve fibres in the VIIIth cranial nerve, and the auditory brainstem, thalamus and thalamocortical radiations (Hall, 1992).

Clinical advantages of ABR include the fact that it is relatively easy to record, objective, non-invasive, is independent of state of subject arousal, is generally drug resistant, and provides ear-specific information (Hall, 1992; Musiek, Borenstein, Hall \& Schwaber, 1994). Furthermore, $A B R$ results provide reproducible, sensitive and quantitative clinical information that can localise lesions within the auditory pathway even when the patient's history and physical examination are normal (Chiappa \& Young, 1985).

As a result of its many advantages, the ABR is now established as the best audiological and oto-neurological test of the functional integrity of eighth cranial nerve and au- ditory brainstem (the so called "site of lesion" or "diagnostic" ABR). In this application, the ABR has proven to be more sensitive in detecting mass lesions than a computerised tomography scan (but less sensitive than an magnetic resonance imaging scan), and more sensitive than any test in detecting functional lesions of the VIIIth CN and auditory brainstem (Hall, 1992; Stanton \& Cashman, 1997).

As the ABR is an accepted test of VIIIth CN and auditory brainstem function, it has also been widely and successfully used as estimator of hearing thresholds (the so called "threshold" ABR). In this role the $A B R$ is used to estimate hearing thresholds in difficult to test subjects such as high risk newborn infants, the mentally and physically handicapped and psychogenic hearing losses (Hall, 1992).

The ABR is not without significant limitations however. Of primary concern is the fact that the ABR is NOT a test of hearing. The perceptual act of hearing requires, at the very least, neural activity to occur in the cortex. As the $\mathrm{ABR}$ is a test of the VIIIth CN and auditory brainstem only, it cannot be used to comment on cortical function. The ABR cannot, therefore, be seen to reflect the conscious act of hearing (Hall, 1992; Roush \& Matkin, 1994).

Other ABR limitations include the need for sufficient peripheral hearing to enable accurate VIIIth CN and audi- 
tory brainstem site of lesion evaluation (Hall, 1992), and the high frequency emphasis of the click stimulus and less than ideal error margin ( $\pm 20 \mathrm{~dB})$ when using ABR to estimate hearing thresholds (Eggermont, 1984; Bachmann \& Hall, 1997).

Whilst there is no doubt the ABR is a powerful component of the advanced audiological and otoneurological test battery, poor knowledge of the ABR's advantages and disadvantages have lead to its serious misuse in many clinical settings by both audiologists and medical doctors (Ferraro \& Durrant, 1994). In a retrospective record review study, Holland (1996) and Downs (1996) showed 13/ 15 Southern African hearing impaired children from 15 to 74 months old to have been successfully assessed using behavioural audiometry after being initially assessed using $A B R$. They concluded the initial ABR assessment to have been unnecessary and to have delayed the initiation of appropriate aural rehabilitation in all 13 cases.

Such misuse of $A B R$ is often related to the extent and nature of professional training in auditory evoked potentials. As Ear, Nose and Throat (ENT) specialists are often the first medical professional to be consulted about an auditory pathology, and the most likely to refer a patient for ABR testing, they are the medical professionals in the most need of up-to-date and accurate ABR training. In view of the under-utilisation of ABR technology in South Africa to date, and the fact that a substantial number of ENT specialists presently practising in South Africa were trained before the peak era of ABR technology, there is a likely demand for continued ABR education of South African ENTs. Without adequate training, underutilisation and inappropriate utilisation of $A B R$ technology will continue (Donohoe, 1988).
By the year 2000, South Africa's population is projected to reach 47 million, the health of whom is expected to be managed within a primary health care framework (African National Congress, 1994). In view of the potential of ABR for early identification of auditory pathologies and hearing loss both as a screening tool and a diagnostic tool, and the emphasis in the White Paper for the Transformation of the Health System in South Africa (1997) on the appropriate use of health technology, the current knowledge and training of South African ENTs on ABR needs to be evaluated.

\section{METHODS}

\section{$A I M$}

This study used a postal survey based questionnaire to investigate ENT surgeon's and registrar's levels of training in; knowledge about; and appropriateness of referral for; auditory brainstem response testing specifically, and its place within audiological site of lesion and threshold testing generally, in Gauteng, South Africa. Specifically this study aimed to:

1 Determine the extent and nature of training received by ENTs in, and;

2 Explore ENTs' perceptions regarding the adequacy of their training in;

ABR testing specifically, and audiological site of lesion and threshold testing generally, and to;

3 Evaluate the referral criteria employed by ENTs for, and;

4 Determine ENTs' views with regard to their need for further training in; ABR testing specifically.

TABLE 1: Description of respondents $(n=37)$

\begin{tabular}{|c|c|c|c|}
\hline Demographic Factor & Sample & Total & Percentage \\
\hline 1. Level of Training & $\begin{array}{l}\text { Registrar } \\
\text { Consultant }\end{array}$ & $\begin{array}{c}7 \\
30\end{array}$ & $\begin{array}{l}19 \% \\
81 \%\end{array}$ \\
\hline 2. University of Graduation & $\begin{array}{l}\text { Cape Town } \\
\text { Medunsa } \\
\text { Bloemfontein } \\
\text { Pretoria } \\
\text { Stellenbosch } \\
\text { Witwatersrand } \\
\text { Other }\end{array}$ & $\begin{array}{c}1 \\
2 \\
1 \\
10 \\
2 \\
20 \\
1\end{array}$ & $\begin{array}{c:}3 \% \\
5 \% \\
3 \% \\
27 \% \\
5 \% \\
54 \% \\
3 \%\end{array}$ \\
\hline 3. Years of Practice & $\begin{array}{l}\text { Less than } 1 \text { year } \\
1-3 \text { years } \\
4-6 \text { years } \\
7-10 \text { years } \\
10 \text { or more years }\end{array}$ & $\begin{array}{c}3 \\
3 \\
9 \\
7 \\
15\end{array}$ & $\begin{array}{l}8 \% \\
8 \% \\
24 \% \\
19 \% \\
41 \%\end{array}$ \\
\hline $\begin{array}{l}\text { 4. Place of Employment } \\
(\mathrm{n}=51)^{*}\end{array}$ & $\begin{array}{l}\text { Government Hospital } \\
\text { Private Practice } \\
\text { University }\end{array}$ & $\begin{array}{c}27 \\
16 \\
8\end{array}$ & $\begin{array}{l}73 \% \\
43 \% \\
21 \%\end{array}$ \\
\hline $\begin{array}{l}\text { 5. Predominant Patient Population } \\
(\mathrm{n}=139)^{*}\end{array}$ & $\begin{array}{l}\text { Infants }(0-18 \text { months }) \\
\text { Paediatrics ( } 19 \text { months - } 11 \text { years }) \\
\text { Adolescents }(12-17 \text { years }) \\
\text { Adults ( } 18 \text { years }+)\end{array}$ & $\begin{array}{l}34 \\
34 \\
35 \\
36\end{array}$ & $\begin{array}{r}92 \% \\
92 \% \\
95 \% \\
97 \%\end{array}$ \\
\hline
\end{tabular}

$* n \neq 37$ as respondents could reply in more than one category. 


\section{PROCEDURE}

\section{Subject sampling procedure and selection criteria}

Subjects were sampled using a convenience sampling technique from the names of 90 ENTs and ENT Registrars listed as members of the South African Society of Otorhinolaryngology, Head and Neck Surgery.

In order to be eligible for inclusion in the survey, all subjects were required to be either actively practising as qualified ENT Specialists or be ENT Registrars completing their training. Due to time and resource restraints, only subjects practising in Gauteng Province, South Africa, were selected.

\section{Description of subjects}

Of the 90 subjects who received questionnaires, 37 responded yielding a response rate of $41 \%$. Moser and Kalton (1971) report that a $20-30 \%$ response rate is acceptable as a baseline of replies to mailed questionnaires, and in general, a response rate below $50 \%$ is not unusual for postal surveys. A description of the respondents is provided in Table 1.

\section{Questionnaire}

The questionnaire comprised of 20 close ended multiple choice questions divided into five sections: demographic information (five questions); extent, nature and perceived adequacy of training in ABR and related audiological/otological tests (six questions); nature of current $A B R$ referral practises (seven questions); need and desire for additional information in various areas of ABR (two questions); and an additional comments section that allowed for open ended comments to be made.

\section{Data analysis}

Questionnaire responses were analysed using descriptive statistics. Responses to multiple choice questions were assessed for percentages of respondents choosing each response. Responses to the open ended comment question were subjectively assessed for themes common across multiple respondents, or on individual comments considered to be of interest. General conclusions were then made.

\section{RESULTS}

The results are presented in accordance with the subaims formulated for the study:

\section{UNDERGRADUATE AND PROFESSIONAL TRAIN- ING}

\section{Respondent's training in the field of $A B R$}

Of the 37 respondents, $19(51 \%)$ had received formal training in the ABR. For these 19 respondents, $2(11 \%)$ received the training during their undergraduate courses, 16 (84\%) during their time as an ENT registrar, and 1 (5\%) during their time as a qualified ENT surgeon. Three of the $19(16 \%)$ had their training conducted by an audiologist and ENT, whilst the remaining 16 (84\%) had their training conducted by an audiologist only. Many of the 19 respondents received their $A B R$ training in multiple formats with $13(68 \%)$ responses for formal lectures, $6(31 \%)$ for workshops, $4(21 \%)$ for conferences, $5(26 \%)$ for journal clubs, and $10(53 \%)$ for self-reading of the literature. This training was for more than 10 hours in $6(32 \%)$ cases, between 5 -10 hours in $4(21 \%)$ cases, between $1-4$ hours $8(42 \%)$ cases, and was less than one hour in $1(5 \%)$ case.

TABLE 2: Numbers and percentages of respondents who had received training in other audiological and/or electrophysiological tests $(\mathbf{n}=37)$.

\begin{tabular}{|l|c|c|}
\hline Audiologic/Electrophysiological Test & Total & Percentage \\
\hline Visual Reinforcement Audiometry & 8 & $22 \%$ \\
\hline Conditioned Orienting Reșponse Audiometry & 3 & $8 \%$ \\
\hline Play Audiometry & 7 & $19 \%$ \\
\hline Tangible Reinforcement Operant Conditioning Audiometry & 2 & $92 \%$ \\
\hline Pure Tone Air and Bone Audiometry & 33 & $78 \%$ \\
\hline Speech Audiometry & 28 & $28 \%$ \\
\hline Site-of-Lesion Testing (e.g., Bekesy Audiometry) & 10 & $31 \%$ \\
\hline Otoacoustic Emissions & 11 & $17 \%$ \\
\hline Electrocochleography & 6 & $11 \%$ \\
\hline Auditory Middle Latency Response & 4 & $0 \%$ \\
\hline Auditory P300 Response & 0 & $0 \%$ \\
\hline Auditory 40 Hz Response & & \\
\hline
\end{tabular}


Respondent's training in other audiological site of lesion and threshold tests

Percentages of the 37 respondents who had received training in other audiological and/or electrophysiological tests are shown in table 2.

\section{PERCEIVED ADEQUACY OF TRAINING}

The respondents average perceived adequacy of training in ABR anatomy and physiology, clinical applications, clinical limitations, interpretation, and referral criteria is shown in figure 1 . Their perceived adequacy of training in audiology in general is shown in figure 2 with the five point scale from one-poor to five-excellent showing percentages of responses of $17 \%$ for one, $22 \%$ for two, $47 \%$ for three, $8 \%$ for four, and $6 \%$ for five.

\section{RESPONDENT'S CURRENT LEVEL OF REFERRAL FOR ABR}

Professional to whom respondents refer for $A B R$ testing

Thirty-five (94\%) respondents indicated they refer to an audiologist for ABR testing. Two (3\%) indicated they refer to an audiologist and neurologist, whilst $2(3 \%)$ indicated they refer to a medical technologist.

\section{Reasons for ABR referral}

Fourteen (37\%) respondents indicated they refer for ABR testing for threshold estimation, $9(26 \%)$ for threshold diagnosis (exact threshold identification), and 14 (37\%) for site of lesion purposes.

\section{Confidence in $A B R$ results}

The respondent's average confidence in the accuracy of ABR results for site of lesion purposes, for threshold estimation purposes, and for fitting of amplification, is shown in figure 3 .

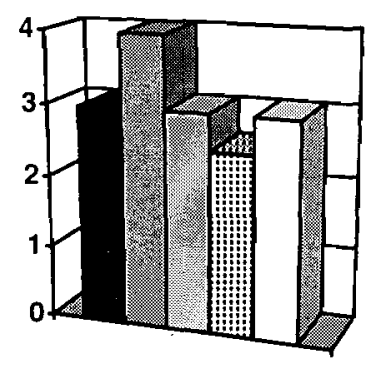

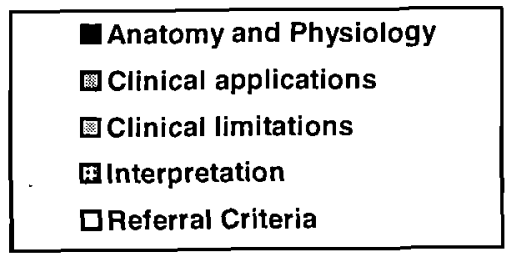

FIGURE 1: Average responses (0-very poor to 5-very good) for respondent's perceived adequacy of training in $A B R(n=19)$.

\section{Access to ABR resources}

The respondent's level of access to ABR is shown in figure 4 with the five point scale from one-low to five-high showing percentages of responses of $6 \%$ for one, $6 \%$ for two, $11 \%$ for three, $25 \%$ for four, and $52 \%$ for five.
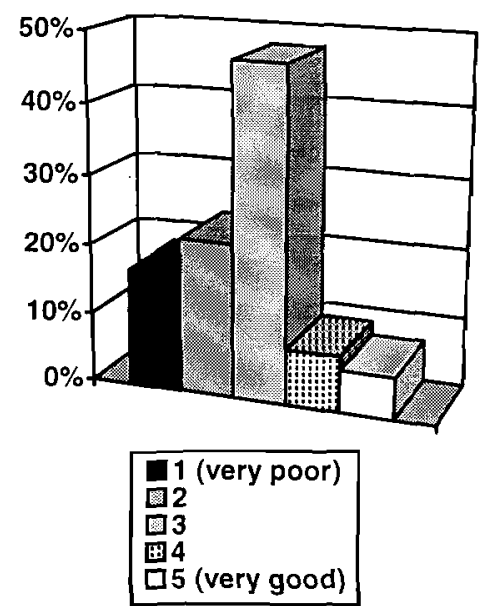

FIGURE 2: Percentage of respondents in each category for perceived adequacy of training in audiology in general $(n=37)$.

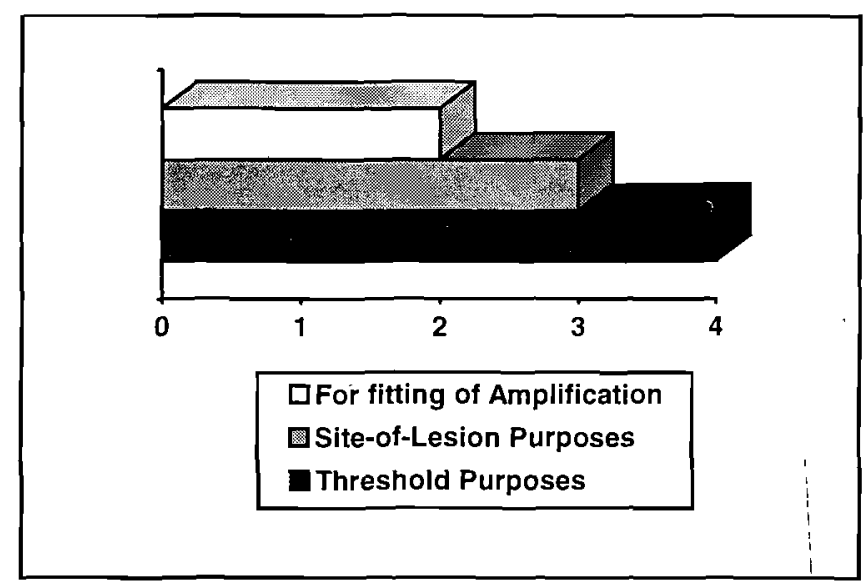

FIGURE 3: Average responses (0-low to 5-high) for respondent's confidence in $A B R$ results $(n=37)$.

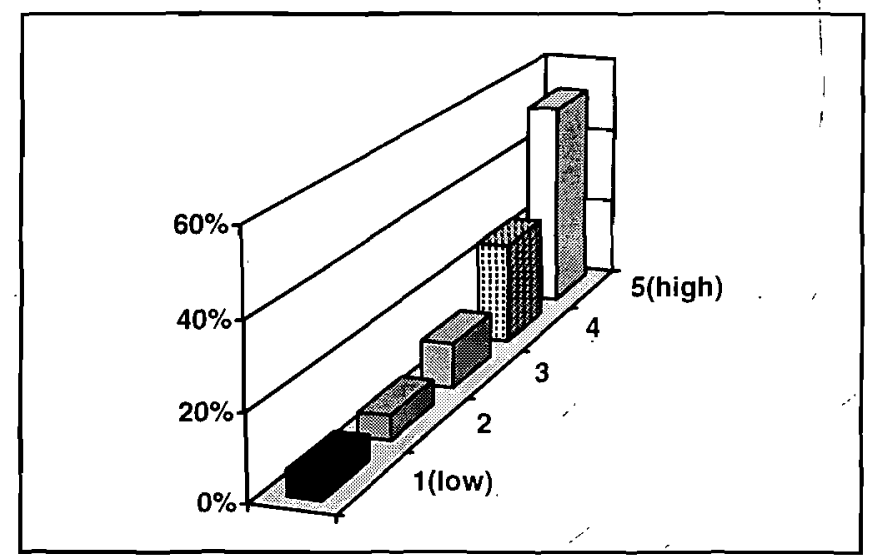

FIGURE 4: Percentage of respóndents in each category (1-low to 5-high) for level of access to ABR $(\mathbf{n}=\mathbf{3 7})$. 
Referral of paediatric and difficult-to-test patients for ABR threshold testing PRIOR to other audiological testing

Twenty-four (64\%) respondents said they would refer neonates ( $0-3$ months old), 26 (69\%) infants (4-18 months old), $11(31 \%)$ toddlers (19 months - 4 years old), $3(8 \%)$ children (5-11 years old), 12 (33\%) physically disabled patients, and $29(78 \%)$ mentally retarded clients, prior to any other audiological testing.

\section{Indication for $A B R$ testing of various pathologies, signs and symptoms}

Table 3 shows respondent's responses as to the indication for ABR testing of various pathologies, signs and symptoms.

\section{NEED FOR ADDITIONAL ABR INFORMATION}

\section{Respondent's perceptions regarding the type of $A B R$ information that is required}

Six $(16 \%)$ of the 37 respondents reported they did not, and $31(84 \%)$ reported they did require further ABR train- ing. Of the 31 respondents requesting further $A B R$ training, $22(70 \%)$ requested training on referral criteria for $\mathrm{ABR}$, $28(90 \%)$ on interpretation of ABR results, $25(80 \%)$ on the clinical limitations of ABR, $30(97 \%)$ on the clinical applications of $\mathrm{ABR}$, and $21(67 \%)$ on the anatomy and physiology of ABR. Twenty-three (73\%) of these 31 respondents preferred this information to be presented in a workshop format, $4(13 \%)$ preferred a conference format, and $11(37 \%)$ preferred a lecture format. Twenty nine (94\%) of these 31 respondents preferred this information to be presented by an audiologist, whilst $1(3 \%)$ preferred a neurologist, and 1 (3\%) a medical technologist.

\section{ADDITIONAL COMMENTS}

In the final item of the questionnaire, respondents were given the opportunity to express any further comments. This question was formulated as an open-ended item. The following are comments that were recorded verbatim:

"In all cases I will prefer otoacoustic emission testing prior to ABR if available."

"Unavailability of ABR in my region is the main reason for my low referral rate. For screening purposes, OAE's seem to be taking over."

TABLE 3: Respondent's responses (n=37) as to the indication for ABR of various pathologies, signs and symptoms (" indicates moderate and "*: indicates major literature support for ABR use).

\begin{tabular}{|c|c|c|}
\hline PATHOLOGY & Total & Percentage \\
\hline Otosclerosis & 2 & $6 \%$ \\
\hline Ossicular Discontinuity & 1 & $3 \%$ \\
\hline Cochlear Pathologies * & 18 & $50 \%$ \\
\hline Presbycusis * & 3 & $8 \%$ \\
\hline Tinnitus, Vertigo, Hearing Loss $* *$ & 30 & $83 \%$ \\
\hline Recruitment* & 16 & $44 \%$ \\
\hline Poor Speech Discrimination *: & 21 & $58 \%$ \\
\hline Tone Decay : & 20 & $56 \%$ \\
\hline Intra-axial Brainstem Leșions & 20 & $56 \%$ \\
\hline Extra-axial Brainstem Lesions & 20 & $56 \%$ \\
\hline Demyelinating Lesions of the Brainstem *: & 23 & $64 \%$ \\
\hline Cerebral Vascular Disease in the Acute Stages & 19 & $53 \%$ \\
\hline Cerebral Vascular Disease in the Recovery Stages & 9 & $25 \%$ \\
\hline Hydrocephalus * & 10 & $28 \%$ \\
\hline Comatose Patients * & 19 & $53 \%$ \\
\hline Intra-Operative Monitoring of Neurological Status after Brain Injury * & 16 & $44 \%$ \\
\hline Intensive Care Unit Monitoring * & 20 & $56 \%$ \\
\hline
\end{tabular}


"ABR is LESS important in ENT than in general and otoneurology. Developments in audiology and radiology are surpassing its diagnostic ability. The high costs of ABR will serve to limit its use in battery testing in a managed care environment."

"In my opinion, MRI scanning has replaced ABR for diagnosis of pathology regarding intra-cranial tumours, CV disease, comatose patients, M.S. ABR is suitable for threshold testing in small children and malingerers." "Depending on costs and logistics a lot more patients could be referred for ABR."

"Education is very necessary for the ENT specialist."

"I have chosen an audiologist to now train me in ABR because I do not know how much information others have on ABR."

\section{DISCUSSION}

This study used a postal survey based questionnaire to investigate ENT surgeon's and registrar's levels of training in, knowledge about, and reasons for referral for, auditory brainstem response testing. Specifically the aims of the study were to; determine the extent and nature of training received by ENTs in, and explore ENT's perceptions regarding the adequacy of their training in, $A B R$ testing specifically and audiological site of lesion and threshold testing generally; and evaluate the referral criteria employed by ENT's for, and to determine ENT's views with regard to their need for further training in, ABR testing specifically. Thirty-seven actively practising ENT Specialists and seven ENT Registrars from Gauteng Province, South Africa were sampled using a convenience sampling technique. Their questionnaire responses will now be discussed in the order of the study's aims.

\section{UNDERGRADUATE AND PROFESSIONAL TRAINING}

With only $51 \%$ of the respondents having received any formal training in $\mathrm{ABR}$, the precedent for poor ENT ABR knowledge was immediately set. The finding that the majority ( $84 \%$ ) of this $51 \%$ received their training during their registrar period was not surprising considering the specialist auditory nature of the ABR. The vast majority ( $87 \%$ ) of respondents with $A B R$ training were trained by an audiologist, whilst the remainder (13\%) were trained by an ENT and audiologist. This shows that when formal ABR training did occur, the professional of choice for $A B R$ training, i.e., the audiologist, was involved.

On closer examination of the $51 \%$ of respondents who had received formal ABR training, the quality of this training seems questionable with the lecture (68\%) and personal reading of literature $(53 \%)$ methods being the dominant form of education. Audiology Curriculum Guidelines for Otolaryngologists recommend that students need to observe and participate in testing that they are involved in (Campbell, 1995). Whilst such recommendations promote the workshop method as being the ideal (Kimura, 1985; Caffarella, 1994), only $31 \%$ of respondents with ABR training received it in this format. The finding that only $53 \%$ of respondents with $A B R$ training reported reading $A B R$ literature is also concerning considering the literature review is perceived as the most basic form of continuing education and a primary strategy for developing understanding and skills (Moll, 1974).

Further effecting the quality of ENT ABR training is the finding that only a minority of respondents (32\%) received training that extended for a time period of greater than ten hours. Because ABR testing is continually evolving technologically, continuing education programmes of less than 10 hours are unlikely to have kept the respondents up to date in the field (Kimura, 1985). Such brief durations of training commonly educate solely in terms of clinical applications, and run the risk of generating false senses of competence (Kimura, 1985).

Whilst ABR training was generally poor, overall training in audiology was somewhat improved, but was still far from ideal (table 2). Whilst the majority of respondents (as many as $92 \%$ ) had received training in basic audiological procedures, only a minority of respondents (as few as $0 \%$ ) had received training in all areas of diagnostic and threshold audiology. This result is concerning considering the well accepted fact that a test battery approach is vital in any assessment of hearing (Hecox \& Jacobson, 1984; ASHA, 1989).

With the increased recognition of $A B R$ as an effective screening method for evaluating hearing in young infants, such incomplete knowledge of audiological test procedures also puts ENTs at risk of inappropriately referring for, or over-utilising, electrophysiological tests in lieu of classic behavioural methods. Such a problem would be consistent with literature reports of inappropriate referrals of children aged five to 74 months for immediate ABR testing when behavioural audiometry was the preferred first test of choice (Widen, 1990; Hodgson, 1994; Downs, 1996; Holland, 1996). A comprehensive knowledge of all audiological tests is required by ENTs because, in certain clinical applications, these tests surpass ABR in terms of their diagnostic and threshold capabilities (Cornacchia, Viglian \& Arpipini, 1982; Folsom, 1990; Hall, 1992).

Overall, the "extent and nature of ABR training received by ENTs" results suggest that the current education of ENT's in terms of ABR specifically, and audiology generally, is unsatisfactory and supports the many literature reports of a shortage of clinical training opportunities for those who are no longer attending academic institutions (Hall, 1992).

\section{PERCEIVED ADEQUACY OF TRAINING}

Whilst the "extent and nature of ABR training received by ENTs" results suggest that the current education of ENT's in $A B R$ is unsatisfactory, on average respondents who had received prior $A B R$ training perceived this training to be of a generally good standard (Figure 1). This was particularly true in the areas of clinical applications of $A B R$, less so in the anatomy and physiology, clinical limitations and referral criteria of $A B R$, and not so for interpretation of $A B R$. Such results are useful in further identifying the areas of ABR knowledge that the ENTs themselves perceive as being their most inadequate.

Whilst those ENTs who have received formal ABR training perceived it to be of a generally high standard, on average, the majority of all ENT respondents (86\%), felt their overall adequacy of training in audiology in general was average to very poor (Figure 2 ). This perception 'was supported by the low numbers of responses given (as low as $0 \%$ ) for actual training received in many of the audiological tests listed in table 2. Such poor perceived and actual training in audiology does not provide a good platform for training in more advanced audiological procedures such as ABR. 


\section{RESPONDENT'S CURRENT LEVEL OF REFERRAL FOR $\boldsymbol{A B R}$}

All respondents indicated that they refer for ABR testing, with the overwhelming majority (97\%) referring to an audiologist. Considering the poor level of knowledge of ABR amongst the ENTs surveyed, the fact that they are all referring for ABRs is concerning. The concurrent finding that these referrals are to audiologists predominantly is reassuring, however, as it provides a safety net for the filtering of unnecessarý referrals.

Reasons for referring for $A B R$, and confidence in $A B R$ results, were less promising with $63 \%$ of the respondents stating that they refer for threshold estimation or threshold diagnosis purposes, compared to only $37 \%$ for site-oflesion testing. Similarly, respondent's confidence in ABR results was, on average, higher for threshold assessments than for site of lesion assessments (Figure 3). These findings do not comply with the literature that states the ABR is at its most sensitive and specific when used as a site of lesion tool in an audiological/otoneurological test battery, and is less sensitive and specific when used as a threshold estimation tool (Hall, 1992; Stanton and Cashman, 1997) where the ABR's subcortical properties and poor accuracy in estimating hearing thresholds prevent it from being a true test of hearing (Weber, 1994). The poor confidence, on average, in $A B R$ as a useful tool in hearing aid fitting was consistent with the literature (Kileny, 1982; Gorga, Beuchaine \& Reiland, 1987; Seitz \& Kisiel, 1990).

Following on from the skewed preference for ABR use as a thresholding tool, was the $69 \%$ of respondents who indicated that they would immediately refer an infant (418 months) for ABR testing without obtaining prior behavioural measurements. This data conflicts with abundant literature on infant paediatric audiological testing which asserts that it is in the neonatal (0-3 months) population that the clinical applications of ABR measurements are especially salient (ASHA, 1989; Folsom, 1990; Joint Committee on Infant Hearing, 1991; Sininger, Abdala \& ConeWesson, 1997), whilst behavioural audiometry is preferred for children who are old enough to be conditioned (generally over four months old) (ASHA, 1991). The numbers of respondents who would immediately refer toddlers (19 months to 4 years) (31\%), children (5 to 11 years) ( $8 \%$ ), and the mentally and the physically retarded (78\%) for ABR assessment were more in line with relevant $A B R$ guidelines (Silman \& Silverman, 1991; Hall, 1992; Hood, 1995), but still demonstrated an overeagerness for immediate ABR referral.

In agreement with the poor ABR knowledge levels shown previously was the respondents poor responses to appropriate and non-appropriate indicators for ABR referral (table 3), despite the literature coverage of this area being extensive (Hall, 1992; Musiek et al., 1994; Hood, 1995; Stanton \& Cashman, 1997). The major ABR indicators (listed as tinnitus, vertigo and hearing loss) and contraindicators (listed as otoschlerosis, ossicular discontinuity and cerebrovascular disease) were well identified (as high as $83 \%$ ), but many respondents missed (as low as $8 \%$ ) other, less obvious, direct and indirect $A B R$ indicators (listed as poor speech discrimination, tone decay, intra and extra-axial brainstem lesions, and demylinating lesions of the brainstem, cochlear pathologies, presbyacusis, recruitment, hydrocephalus, comatose patients, intra-operative monitoring after brain injury, and ICU monitoring).
Whilst the respondents showed evidence of poor $A B R$ knowledge and training, most ( $88 \%$ ) (figure 4) also reported having an average to high access to ABR. Such accessibility reinforces the need for appropriate education to prevent the underutilisation of, and inappropriate referral for, ABR testing.

Overall, the "respondent's current level of referral for ABR" results were consistent with the "extent and nature of $A B R$ training received by ENTs" results and further suggest a need to improve ENT knowledge of ABR specifically, and audiology generally.

\section{NEED FOR ADDITIONAL ABR INFORMATION}

The respondents showed an overwhelming desire (84\%) for additional information and gave strong indications of the areas they want covered and the way the information should be presented. According to the majority of ENTs surveyed in this study, ABR education in the ENT population needs to be:

- Primarily in the areas of interpretation, clinical limitations and clinical applications of ABR, then in referral criteria, and then the anatomy and physiology underlying the technique.

- Presented in practical workshops rather than conferences and lectures.

- Presented by audiologists.

\section{ADDITIONAL COMMENTS}

These verbatim responses indicated that some respondents in the study felt that both oto-acoustic emissions as well as magnetic resonance imaging were transcending ABR in terms of their diagnostic abilities in both audiology and otoneurology. However, in direct contrast to this, other respondents also indicated that because of its high cost and inaccessibility, ABR is not sufficiently employed . Lastly, the need for further training was also highlighted. Respondents thus again, appeared willing and motivated to increase their knowledge with regard to ABR. This has implications for the provision of future education.

\section{CONCLUSIONS}

Overall, a poor level of training and knowledge in ABR and its related areas of audiology, was identified in the surveyed ENT specialists and registrars in Gauteng. This finding was mirrored by a high demand amongst the respondents for further education in ABR technology, preferably in a workshop format run by a qualified audiologist.

This demonstrated willingness amongst ENTs to further their working knowledge of $A B R$ places the responsibility for this education back on the South African audiology community. The South African audiology community needs to be more active in its attempts to make a larger contribution to the audiological education of its ENT allies, both at undergraduate and postgraduate levels.

The ABR remains essential to the modern practice of hearing medicine. Its proliferation in the last 20 years, and the often limited expertise of its users, has seen the ABR become both over and underutilised in the clinical setting. Considering the prevalence of auditory disorders in South Africa, it is hoped that this study's results will heighten the need for improved awareness of ABR in ENT surgeons 
and registrars. An improved awareness will motivate increased training in $A B R$, the enforcement of correct referral guidelines, and further research into ABR and related areas. Such endeavours are likely to lead to a refined use of $A B R$ in South Africa, which in turn should result in improvements in the provision of hearing health care to the population at large.

Limitations of this study include the relatively small and restricted ENT population sampled. These limitations prevent this study's results from being generalised beyond the ENT surgeon and registrar population practising in Gauteng, South Africa.

Note: The questionnaire used in this study is available on request from the corresponding author; Wayne Wilson, Department of Speech Pathology and Audiology, University of the Witwatersrand, Private Bag 3, WITS, 2050, South Africa. Email: 053wayne@muse.wits.ac.za.

\section{REFERENCES}

African National Congress. (1994). A National Health Plan for South Africa. Johannesburg: African National Congress.

American Speech, Language and Hearing Association. (1989). Guidelines for audiological screening of newborn infants who are at risk for hearing impairment. ASHA, 31, 89-92.

American Speech-Language-Hearing Association. (1991). Guidelines for the audiological assessment of birth through 36 months of age. ASHA, 33 (suppl.5), 37-43.

Bachmann, K.R. \& Hall, J.W. (1997). Paediatric auditory brainstem response assessment: The cross-check principle twenty years later. Seminars in Hearing, 19, 41-60.

Caffarella, R.S. (1994). Planning Programs for Adult Learners. San Fransisco: Jossey-Bass Inc.

Campbell, K.C. (1995). Audiology curriculum guidelines for otolaryngologists. American Journal of Audiology, 4, 35-36.

Chiappa, K.H. \& Young, R.R. (1985). Evoked Responses: Overused, Underused, or Misused? Archives Neurology, 42,76-79.

Cornacchia, L., Viglian, E. \& Arpipini, A. (1982). A comparison between brainstem evoked response audiometry and behavioural audiometry in 270 Infants and Children. Audiology, 21, 359-363.

Donohoe, C.D. (1988). Application of the brainstem auditory evoked response in clinical neurologic practice. In Owen, J.H. \& Donohoe, C.D. (Eds.), Clinical Atlas of Auditory Evoked Potentials. New York: Grune and Stratton.

Downs, D. (1996). A retrospective study of unnecessary and neces. sary use of auditory brainstem response testing in paediatric hearing assessment. Paper presented at the Pan African Federation of Oto-Rhino-Laryngological Societies, 3rd Scientific Meeting, 27 October - 01 November 1996, Durban, South Africa.

Eggermont, J.J. (1984). The inadequacy of click-evoked and brainstem responses in audiological application. Annuals of the New York Academy of Science, 388, 707-709.

Ferraro, J.A. \& Durrant, J.D. (1994). Auditory evoked potentials: Overview and basic principles. In Katz, J. (Ed.), Handbook of Clinical Audiology (4th ed.). Baltimore: Williams and Wilkins.
Folsom, R.C. (1990). Identification of hearing loss in infants using auditory brainstem response: Strategies and program choices. Seminars in Hearing, 11, 333-341.

Gorga, M.P., Beuchaine, K.A. \& Reiland, J.K. (1987). Comparison of onset and steady state responses of hearing aids: Implications for use of the $A B R$ in the selection of hearing aids Journal of Speech and Hearing Research, 30, 130-136.

Hall, J.W. (1992). Handbooh of Auditory Evohed Responses. Boston: Allyn and Bacon.

Hecox K. \& Jacobson, J.T. (1984). Auditory evoked potentials. In Northern, J.L. (Ed.), Hearing Disorders. Boston: Little, Brown and $\mathrm{Co}$

Hodgson, W.R. (1994). Evaluating infants and yound children. In J. Katz (Ed.), Handbook of Clinical Audiology (4th ed.). Baltimore: Williams and Wilkins.

Holland, K. (1996). A Retrospective Study of Unnecessary and Necessary Use of Auditory Brainstem Response Testing in Paediatric Hearing Assessment. Unpublished Honours Thesis, Submitted to the University of the Witwatersrand: Johannesburg.

Hood, L.J. (1995). Estimating auditory function with auditory evoked potentials. The Hearing Journal, 48, 10-15.

Joint Committee on Infant Hearing (1991). 1990 Position Statement. ASHA, 33 (Suppl 5), 3-6.

Kileny, P.R. (1982). Auditory brainstem responses as indicators of hearing aid performance, Ann. Otol, 91, 61-64.

Kimura, J. (1985). Abuse and misuse of evoked potentials as a diagnostic test. Archives of Neurology, 42, 78-80.

Moll, K.L. (1974). Issues facing us: Continuing education. ASHA, $16,306-307$

Moser, C.A. \& Kalton, G. (1971). Survey Methods in. Social Investigation. (2nd ed.). London: Heinemann.

Musiek, F.E., Borenstein, S.P., Hall, J.W. \& Schwaber, M.K. (1994). Auditory brainstem response: Neurodiagnosis and intra-operative applications. In Katz, J. (Ed.), Handbook of Clinical Audiology (4th ed). . Baltimore: Williams and Wilkins.

Roush, R., \& Matkin, N.D. (1994). Infants and Toddlers with Hearing Loss: Family Centred Assessment and Intervention. Baltimore: York Press Inc.

Seitz, M.R. \& Kisiel, D.L. (1990). Hearing aid assessment and the auditory brainstem response. In Sandlin, $\mathrm{R}$. (Ed). Handbook of Hearing Aid Amplification. Boston: College Hill Press.

Sininger, Y.S., Abdala, C. \& Cone-Wesson, B. (1997). Auditory threshold sensitivity of the human neonate as measured by the auditory brainstem response. Hearing Research, 104, 2738 .

Silman, S. \& Silverman, C.A.(1991). Auditory Diagnosis: Principles and Applications. New York: Academic Press.

Stanton, S.G. \& Cashman, M.Z. (1997). ABR: A comparison of different strategies for detection of cerebellopontine angle tumours. Scandinavian Audiology, 25, 109-119.

Weber, B.A. (1994). Auditory brainstem response: Threshold estimation and auditory screening. In Katz, J (Ed.). Handbook of Clinical Audiology (4th ed.). Baltimore: Williams and Wilkins.

White Paper for the Transformation of the Health System in South Africa. Government Gazette No 1108 of 1997. Pretoria: Government Printers.

Widen, J.E. (1990). Behavioral screening of high-risk infants using visual. reinforcement audiometry. Seminars in Hearing, $11,343-348$. 


\section{INFORMATION FOR CONTRIBUTORS}

\section{Nature of publication}

The South African Journal of Communication Disorders publishes reports and papers concerned with research, and critically evaluative theoretical and philosophical conceptual issues dealing with aspects of human communication and its disorders, service provision, training and policy.

The South African Journal of Communication Disorders will not accept material which has been published elsewhere or that is currently under review by other publications.

\section{Manuscript style and requirements}

- Articles must be accompanied by a covering letter providing the author's address, telephone and fax numbers and e. mail address.

- Articles must be typed on A4 pages in double spacing and in a font size of 12 .

- Three print-outs of the article must be submitted

- ONE exact copy of the article on disk must be submitted. Filenames must include the first author's initials and a clearly identifiable key word and must be type-written on the last line of the last page of the Reference list (for retrieval purposes only).

- Articles must not exceed $\underline{30}$ pages.

- The title page of ONE must contain:

- Title of the article.

- Full names of the author/s.

- Institutional affiliation.

- Abstract of the article in the language of the article.

- The title page of the remaining TWO copies must NOT contain the author/s name/s or institutional affiliations.

- Each article must contain an abstract of no more than 200 words.

- All abstracts must be in ENGLISH, irrespective of the language in which the article was written

Each article must provide 5-7 KEY WORDS for indexing purposes.

- All contributions are required to follow strictly, the style specified in the Publication Manual of the American Psychological Association (APA Pub. Man., 1983)

- Headings are NOT NUMBERED. The order of importance is indicated as follows:

- Main heading in capitals and bold print

- Sub-headings in capitals, bold and italic print.

- Sub-subheadings in upper and lower case bold and italic print.

- Sub-sub-sub-heading in upper and lower case bold print.

- Major headings, where applicable, must be in the order of INTRODUCTION, METHOD, RESULTS, DISCUS. SION, CONCLUSION, ACKNOWLEDGEMENTS, REF. ERENCES.

- All paragraphs should be indented.

- All tables, figures and illustrations must be numbered and provided with titles.

- The title of tables, which appear above, and of figures, which appear below, must be concise but explanatory.

- Allow for $.50-75 \%$ reduction in printing of tables, figures an illustrations.

- Each table, figure or illustration must appear on a SEPARATE page and be print ready. Preferable NOT printed on colour printers.

- Do not include more than 10 tables, figures or illustrations.

\section{REFERENCES}

- References must be cited in the text by surname of the author and the date, e.g., Van Riper (1971).

- Where there are more than two authors, after the first occurrence, et al. may be used from the start.

- The names of all authors must appear in the Reference List," which must be listed in strict alphabetical order in triple spacing at the end of the article.

- All references must be included in the List, including secondary sources, (APA Pub. Man. 1983, p. 13.)

- Only acceptable abbreviations of journals may be used, (see DSH ABSTRACTS, October; or The World List of Scientific Periodicals).

- The number of references should not exceed much more than 30 , unless specifically warranted.

\section{EXAMPLES}

Locke, J.L. (1983). Clinical Psychology: The explanation and treatment of speech sound disorders. J. Speech hear. Disord., 48 339-341.

Penrod, J.P. (1985). Speech discrimination testing. In J. Katz (Ed.), Handbook of clinical audiology ( $3^{\text {rd }}$ ed.). Baltimore: Williams \& Wilkins.

Davis, G.A. \& Wilcox, M.J. (1985). Adult aphasia rehabilitation: Applied pragmatics. San Diego, CA: College-Hill.

\section{EDITING}

- Articles must be revised for grammar and style prior to submission.

- The manuscript style of the article must be strictly according to the guidelines provided.

- Only articles complying with the above requirements will be accepted for review.

\section{REVIEWING SYSTEM}

- The peer review of refereeing system is employed as a method of quality control of this publication.

- Peer reviewers are selected by the editor based on their expertise in the field and each article is sent to two independent reviewers to assess the quality of the manuscript's scientific and technical content.

- The blind peer review system is employed during which the names of the author/authors are not disclosed to the reviewers.

- The editor retains the final responsibility for decisions regarding revision, acceptance or rejection of the manuscript.

DEADLINE FOR CONTRIBUTIONS: $30^{\text {th }}$ June each year.

QUERIES, CORRESPONDENCE \& MANUSCRIPTS: should be addressed to The Editor, South African Journal of Communication Disorders, South African Speech-Language-Hearing Association, P.O. Box 91042, Auckland Park. 2006. Tel. 011/726-5014, Fax. 011/726-5013.

\section{Copyright}

The copyright of all articles printed in The South African Journal of Communication Disorders is reserved by The South African Speech-Language-Hearing Association (SASLHA). 